\title{
Research on the Elimination of Negative Value of Big Data Technology
}

\author{
Maoxin Tian \\ Xichang University \\ Xichang, Liangshan Prefecture, China
}

\begin{abstract}
With the rapid development of big data technology in recent years, data has become new resource for the entire society. People are rushing to research big data. While using big data technology, it also inevitably leads to the reflection on the duality of technology value. Therefore, the duality of big data technology has become the logical starting point for this article. In studying the academic atmosphere of big data technology, the negative value of big data technology always appears at a high frequency and is discussed by people. Humans worry that the realization of negative security, ethics, and other issues brought about by negative values will give individuals and the society unimaginable disasters. To eliminate and avoid the negative values of big data technology has become a research hotspot. Moreover, in the historical period of China's economic and social transformation, research on these issues has become more urgent.
\end{abstract}

Keywords—big data technology; positive value; negative value; elimination

\section{INTRODUCTION}

According to the duality of technical value, the elimination of negative value of big data technology mainly refers to the efforts to reduce and coordinate the negative value of big data technology. The realization of the positive value of big data technology and the realization of the negative value of big data technology are dialectical and united. In fact, with the current development of technology, there is no technology that only realizes positive values. On the contrary, there is no technology that realizes negative values. For humans, it has distinction among the strength of realization. There is such unavoidability between negative values and positive values. And we should rationally look at the realization of the negative value of big data technology. To a certain extent, we should eliminate the negative impact of the negative value of big data technology on human beings. Therefore, this paper will separately discuss the elimination of negative value of big data technology from three aspects.

\section{TeChNOLOGY Elimination OF NeGATIVE VALUE OF BIG DATA TECHNOLOGY}

For this article, the technical elimination of the negative value of big data technology is to manage big data through big data. And then, it would achieve self-discipline of technology. Understanding this sentence is very simple. Big data technology is becoming an increasingly important transformative technology. Today, people use the big data technology to realize its positive value. For example, the government uses big data to manage and reduces the management cost. At the same time, the timeliness of management has been improved. Through the mining and analysis of big data technologies among enterprises, many emerging industries that are different from the past have been generated. The potential customer analysis system is based on this result. The bank manages big data through customer groups. Banks have more accurate macro view of society as a whole. The medical insurance can effectively track the physical health of social groups through the application of big data technology, and can even predict whether an outbreak will occur in a certain place. However, the moral, ethical, and privacy security issues that have arisen during the use of big data have also been highlighted. It is clear that people are more passive in the face of the problem of the negative value of big data technology. In terms of coping methods, why do we not want to reflect on the principle of multi-methodology? As some scholars have pointed out: "it should break away from the constraints of logical thinking, break through the imprisonment of traditional ideas, and freely construct possible interactions and connections among them through various messy empirical facts; discover the hidden mechanisms and essence behind them [1]". Multivariate methodology gives us new ideas to eliminate the negative value of big data technology. This is also the inspiration from this article. Using big data technology to manage big data technology is a very effective method. Specifically, big data organizations, big data companies, and big data research labs with national strategy create a big data self-management system that implements standards for all parties involved in the development and application of big data, including the establishment of privacy security assessment system, big data social effect collection system, big data dynamic ethical prediction system, and many other systems with big data technology attributes. In the view of this paper, this is the most effective way for eliminating the negative value of big data technology. Of course, from the perspective of the multi-methodology, there may be many deficiencies in this paper. In this case, the author hops that he could put forward constructive opinions on the elimination of negative values of big data technology. 


\section{The Legal Elimination OF the Negative VAlue OF BIG DATA TECHNOLOGY}

In the technical elimination of the negative value of big data technology, we summarized the new idea of using big data to manage big data. Obviously, if all the negative value of big data technology is handed over to the technology, it would certainly be unsuitable and incorrect. The prevention methods and scope of using big data technology have certain limitations. In order to make up for these blind spots, the emergence of laws has played a positive role in eliminating the negative values of big data technologies to a great extent.

Since the law came into being, the contribution to mankind has been obvious. Its main role is reflected in the normative role and the social role. The normative role of the law emphasizes the guidance, evaluation, prediction, coercion and education of the law on specific people and specific matters. Then, it gave us five legal roles in dispelling the negative value of big data technology.

\section{A. The Guidance Role of Law}

China's first local regulations on big data technology are concerned. The use of big data technology in the practical process will inevitably produce negative value. And the timely introduction of laws and regulations will be helpful to the development and application of this technology. It could guide relevant big data organizations and enterprises to advance the path of positive value realization of big data technology. In this development, the United States, Europe and other western countries do more work. And the United States has many laws and regulations concerning big data. In the contractual social structure they valued, the introduction of these mandatory documents is undoubtedly an innovation for the entire big data industry. To a certain extent, China can refer to their experience. And then, it may better guide the development of the domestic big data technology industry.

\section{B. The Evaluation Role of the Law}

As a kind of evaluation and judgment criterion, the evaluation function of law has been practiced by people for a long time. With the development of big data technology, the data companies' commercial behaviors are mingling with each other. And illegal behaviors are increasing. Why is it illegal? Which law does it violate? At this time, the evaluation role of the law has emerged. However, the analysis of seeking truth from facts in China has only issued certain regulations concerning the protection and application of big data. With a high degree of compulsion, Guizhou province has issued provincial industrial restrictive regulations on it. From the perspective of the universality of legal application, it hasn't implemented in the whole country. And the country has not unilaterally legislated on big data. Many domestic experts and scholars unanimously suggested that legislation should be promoted as soon as possible. The evaluation of the law can be better played out, which will help build a healthy ecological environment for the development of big data technology.

\section{The Predictive Role of the Law}

A patient who feels that he or she is going to be ill would go to the hospital to get a vaccination if he or she predicts that something like this may happen. In general, the law also plays a role in this kind of vaccination in society. A transformative technology industry will not go against the trend. The healthy and sustainable development of enterprises is to comply with the current laws and regulations. Through the legitimate gains, it would achieve their own rapid development. And then, with reference to legal standards, the social effect is obviously the matter of concern and importance to any enterprise. If the law can be enforced, we could do it without any worries. If the restrictions cannot be done, the enterprise or individual will alert it. Of course, the act of knowingly breaking the law does exist; it is equal to the whole. The number is controllable, which fully shows how important the prediction function of the law is to the survival and development of the enterprise. A perfect law can benefit individuals and the society. And the faulty law can also cause huge losses to individuals and society. Although China has not yet promulgated a complete and specific big data law, the laws and regulations in various localities and departments are worthy of reference by other enterprises and individuals. People also hope that relevant legal documents can be issued at an early date. It would facilitate the elimination of the negative value of big data technology.

\section{The Enforcement Function of the Law}

This role of the law is believed to be familiar to everyone. And the law of crime is an iron law from ancient times to the present. And it shows the compulsory role of the law. It is also an important reason why China adheres to the rule of law. As pointed out by General Secretary Xi Jinping, "We have put forward the idea of governing the country according to law in an all-round way unswervingly. One of our important intentions is to plan for future generations and long-term development [2]. From the three points above, it is based on the guidance of the positive value realization of big data technology and the legal norms. It is a kind of restraint of self-discipline. However, in the practice of technology, the behavior of breaking this restriction exists in explicit and implicit ways. And then, the law needs its rigid function to carry on the compulsory regulation. Therefore, the compulsory function of the law has the powerful deterrent power to the realization of the negative value of the big data technology. And it can eliminate the realization of the negative value of the technology to a certain extent.

\section{E. The Educational Role of the Law}

The educational function of the law is mainly reflected in the results of dealing with illegal activities. With the corresponding treatment, it will play an educational role in the absence of similar events. Generally speaking, we can know the legal elimination of negative value of big data technology. At present, there is still a great process of promotion. In the author's opinion, with the establishment and perfection of relevant laws on big data in China, it will 
certainly have a positive energy for the development of the whole technology in the future.

\section{THE ETHICAL ELIMINATION OF THE NEGATIVE VALUE OF BIG DATA TECHNOLOGY}

The elimination of the negative value of big data technology includes the elimination of technology and the elimination of laws. Also, it includes the way of ethical elimination. Ethical elimination is a special way of digestion and has its own unique dispelling features, which is related to the relevant knowledge of the ethical level.

The category of ethics is relatively large. So far, there has not been a universally recognized technology ethics. As some scholars have pointed out, "from Habermas's 'Communication Ethics' to Rawls' 'Theory of Justice', from the "principle of responsibility" of Yunus to Beaz's "consensus model" based on the interference of technology to human fertility, from the "do or not" of Bernbach to Lenk's detailed analysis on the description of the type of responsibility, what we see in the western academic world is the competition among various models and theories [3]. Although there is no universally agreed technical ethics, some of them are worthy of learning and applying to the ethical elimination of the negative values of big data technology. For example, in the view of Habermas's communicative ethics, the dualism of labor and communication is grand narrative of the history of mankind that it has constructed. The humans continue to develop the technology. And it weakens people-to-people exchanges. The relationship between people and things (technologies) has been strengthened. And the differences between the strengths and weaknesses have increased with the progress of technology. Eventually, there has been an explosion in material information, rapid technological development, and a decline in the subjective status of people. And Hama Beski proposed to establish a reasonable mode of communication. He wanted to use exchanges to gradually replace the core position of labor in the entire society. As some scholars have pointed out, "the shift in the focus of historical rationality from the 'subject-object' structure to the 'subject-subject' structure is precisely the rationalization of inter-subjective communicative actions that can eliminate the self-discipline and alienation properties of technology and instrumental rationality [4]". Although the communication ethics of Jurgen Hammarbes has been proposed for half a century, his ethical perspectives on the elimination of this negative value of technology can be used as the reference. It is undeniable that big data technology is similar in many places. With the development of big data technology, it would have databased production. The data-based means of production will bring the rich material resources to the individual and the human society. It is a kind of connection, which makes people easily fall into the situation in the long run. In this situation, it only has technology and themselves. It is obvious that technology and legal deconstruction cannot become the only effective means. Therefore, the ethical elimination of big data technology is very necessary. And it would arouse our vigilance.
In the eyes of another philosopher, responsibility is the only correct way to eliminate the negative value of technology. He learned from the German philosopher Hans Yunus. Yunus's personal experience is very rich. The experience of World War II is a turning point in his life. The technology in his eyes is not so friendly. And his mentor Heidegger is full of pessimism about technology. In his view, responsibility is a structure of relations related to power and knowledge, which interact with each other [5]. In Yunus's opinion, the technology differentiates people into able users and non-users. There is a difference in the structure of power and knowledge between able users and non-users. And this difference ultimately led to the uncontrollable stage of technology and even the abuse stage. It has prompted him to think about the relationship between technology and ethics. The responsibility ethics of Yunus appeared in people's eyes. And he put the entire ethical vision into the future. With a responsibility, the future of technology concept would construct new ethics. In recent years, China's attention on this concept has been greatly improved. Anti-environmental pollution, anti-haze, anti-government inaction and anticorruption issues have caused the consensus of the whole society. This establishment has also contributed to the ethical resolution of the negative value of big data technology.

\section{CONCLUSION}

Starting from the duality of the value of big data technology, positively speaking, it can be an enhancement of the positive value of technology. From the negative point of view, it can be the elimination of the negative value of technology. The two ways can be connected with each other. And then, it would to better comply with the law of the development of the data age. It could provide benefits for the society and the people. In this paper, it has discussed the elimination of negative value of big data technology. There are still many places not involved in this paper. At least, the author has carried such data feelings. Through the discussion, it would make up for the discussion. Similarly, the big data technology has been developed for nearly a decade in China. With the time goes by, China's big data technology is mature. Thanks to the efforts of the Chinese government and people from all walks of life, the technology has made a great deal of development.

Finally, it hopes that China can seize the commanding point of the development of big data technology, contribute data to the harmonious development of national economy and society, and also point out a feasible way of sustainable development of big data technology for global development.

\section{REFERENCES}

[1] Zhang Zhicang, Zhang Xie. Multivariate methodology - Criticism and deconstruction of traditional methodology [M]. Beijing: People's Publishing House, 2012.

[2] Bian Ji. Ren Min. General Secretary Xi Jinping's series of important speech readers [M]. Beijing: Learning Press, 2016.

[3] Li Wenchao. The dilemma faced by technical ethics [J]. Studies in Dialectics of Nature, 2005. 
[4] Han Hong. On the realization of the rationalization of communicative behavior - The core issue of Habermas's communicative action theory [J]. Academic Research, 2002.

[5] Zhu Yanyuan. Responsibility ethics of Hans Jonas [D] Liaoning: Dalian University of Technology, 2005. 